\title{
XXIV. On the different proportions of carbon which constitute crude iron and steel
}

\section{David Mushet Esq.}

To cite this article: David Mushet Esq. (1802) XXIV. On the different proportions of carbon which constitute crude iron and steel , Philosophical Magazine Series 1, 13:50, 142-149, DOI: $10.1080 / 14786440208676104$

To link to this article: http://dx.doi.org/10.1080/14786440208676104

曲 Published online: 18 May 2009.

Submit your article to this journal $\sqsubset \pi$

Џ Article views: 2

Q View related articles $\sqsubset$ 


\section{[ 142$]$}

XXIV. On the different Proportions of Carbon which conftitute Crude Iron and Steel. By David Mushet, Efq. of the Calder Iron Works*.

WI Y laft communication contained feveral experiments to prove the quantity of carbon abforbed by pure malleable iron in paffing into the carbonated crude ftate. The object of the prefent will be to exhibit the proportions of carbon which enter into the compofition of the other varieties of crude iron and caft fteel. I continue the numeration of the experiments from my laft:

Exp. VII Swedith bar iron

Charcoal $\quad-\quad$ II74

A fufion was obtained from this mixture, after which there remained only a fmall portion of charcoal, too minute for weighing.

The metallic button wcighed

Gained in weight by the combination of charcoal equal to $\frac{1}{3}$ th part the weight of the iron.

Weight of the iron 1174 , and charcoal $78,=1252$

Weight of the button - $\quad-\quad 1213$

Total lofs of weight in the fufion $\frac{12}{39}$ equal to that gained by the iron. Upon minute infpection, no part of the furface of this button was carbonated. The colour was blueifh black, fmooth in the centre but a little oxidated towards the edges. Its fracture prefented clofe dark gray crude iron. The cryftals much clofer and more minute than in thofe experiments where richly carbonated crude iron was obtained. Appreciating its real quality by comparifon with crude iron manufactured for fale, it occupied that rank generally known by the names of No. II. gray melting pig iron.

Grs.

Exp. VIII. Swedifh bar iron - $\quad 922$

Charcoal $\frac{1}{2}$ th part, or 46 grs.

From the expofure of this mixture there refulted a very perfect metallic button whofe upper furface prefented a partial degree of radiated cryftallization. It was found to weigh $\quad-\quad$ - $\quad$ - $\quad$ - $95^{\circ}$

Gained in weight by the combination of carbon 28 equal to $\frac{1}{3} \mathrm{~d}$ part the original weight of the iron. The fracture of this button was fmooth, filvery white, occafionally fradded with carbonaceous fpecks in the form of fmall

* Communicated by the Author.

grains, 
grains, an exact refemblance to mottled pic iron. In this experiment there remained not the molt diftant trace of carbonaceous matter. A fmall portion of amber-coloured glafs was formed round the elges of the metal.

Weight of the iron 922 , charcoal $46,=\quad-968$

Metal refulting

Exp. IX. Swedifh bar iron
Charcoal $\frac{1}{2}$ th part, or 53 grs.
From this mixture a perfect fufion and metallic but-

Total lofs of weight $\overline{18}$.

Grains.

$133^{\circ}$

Gained in weight by the combination of carbon $2 \mathbf{I}$ equal to $\frac{1}{6} \mathrm{~d}$ part the weight of the iron. In this experiment alfo the charcoal had completely difappeared. The upper furface of the button was fmooth, the under furface confiderably pitted. The concaves chequered with a rude cryftallization peculiar to caft iron. The fracture of this metallic mals was bright filvery white, deftitute of grain, and exhibiting a very perfect ftreaky cryftallization nightly radiated. Its refemblance was ftrikingly fimilar to that of highly blown caft iron prepared in the finery for the purpofes of bar iron making; an operation commonly in ufe for the purpofe of decarbonating the iron, that it may, in the fubfequent procefs, fooner pals into the ftate of malleability. The weight of iron and charcoal in the experiment amounted to $\mathrm{grs} .13^{8} 3$ Iron obtained

Total lofs in the fufion

Exp. X. Swedifh iron

Charcoal ${ }_{3}^{\frac{1}{3}}$ th, or $45 \mathrm{grs}$.

1348

From this proportion of mixture in half an hour a perfectly fufed button of metal was obtained, which was found to weigh

Gained in weight by the combination of carbon II equal to $\frac{x}{1} d$ part the original weight of the iron. The upper furface of this button was fmooth without configuration. Below the furface was uneven, and covered with minute but perfect cryftallization. Its fracture was blueifh filvery white, compofed of flat dazzling cryftals, proceeding in 


\section{I44 On the different Proportions of Carbort}

lines from a centre to the edges of the button. Here it was mott obvious, that from the fmallnefs of the proportion of carbon prefented to the iron, the refulting product was found affuming the earlieft ftage of granulation approaching to the fteely ftate. The brilliant concretions obfervable in the furface of the button were too indiftinct and flat for fteel capable of withftanding the hammer.

Grains. The joint weight of the iron and charcoal amounted to 1393 Iron obtain

Exp. XI. Swedifh iron Charcoal $\frac{1}{7}$ th, or $37 \mathrm{grs}$.

The metallic button obtained by the fufion of this mixture weighed

Gained in weight by the union of carbon equal to $\frac{1}{50}$ th part the firft weight of iron. The upper furface of this button was fmooth, with a faint impreffion of a chequered cryftallization. The under furface poffeffed fome large pits, fimilarly, though more perfectly cryftallized.

The fracture poffeffed one thade of blue beyond that of No. X. A regular granulated furface compoled of flat oblong cryftals was obfervable, ftill too indiftinct and too much on edge for workable fteel. The weight of charcoal and iron in this experiment amounted to

Metal obtained

grs. 1539

1505

$$
\begin{array}{lll}
\text { Total lofs of weight in the fufion } & 34 \\
\text { Exp. XII. Swedifh iron } & - & -
\end{array}
$$

\section{Total lofs of weight in the fufion}

Charcoal $\frac{x}{5}$ th, or 3 I grs.

From the expofure of this mixture, a metallic button was obtained, which weighed

Loft in fufion, equal $\frac{x}{3 \frac{1}{8}}$ th part. 4 The furfaces of this button were uniformly fmooth. The fracture was denfe, and difplayed a grain peculiar to highly faturated bliftered fteel. When put under the hammer, with a low red heat, it ftood a few blows, but aftewards parted.

Weight of mixture employed in the experiment grs. ${ }_{15} 68$

Steel obtained 
A very fine fufion was produced from the expofure of this mixture. The metallic button was found to weigh

$$
\text { Loft in fufion, equal to } \frac{T}{31 \cdot \frac{0}{10}} \text { th part, }
$$

This button prefented a wavy cryftallized furface. The under furface was rough, and contained one large pit accurately cryftallized. The fracture was regularly granulated, fmall, but diftinct, of a light blueifh colour. The cryftals, though diftinet, were not fo prominent as thofe of eafy drawing calt fteel. It, however, hammered with the ufual degree of caution neceffary to the working of caft fteel. The bar of fteel formed from the button poffeffed all thofe properties requifite for file making, and other purpofes requiring a quality highly charged with carbonaceous matter.

Weight of the mixture

Grains.

Steel obtained

Lofs of weight in this experiment

$$
\text { Exp. XIV. Swedinh iron - }
$$

equal to $\frac{I}{22^{3}}$ th part the original weight of the iron. The furface of this button was fmooth, without cryftallization. The under furface rough, and poffeffed of one large pit in the centre, faintly marked with the ufual cryftalline appearance. The fracture prefented regular light blue grains, dittinst, and more prominent than No. XIII. One-half of the button was drawn into a neat fquare bar, and proved fteel of an excellent quality. One end of the bar being loofe and thaled, welded tolerably well, and hardened afterwards with a low heat. In appreciating the quality of this refult, it appeared to be that kind of fteel fuitable for penknives, razors, \&cc., poffeffed of neither the extremes of hardnefs nor of foftnefs.

Beyond the proportion of $\frac{x}{5}=$ th part of charcoal to iron, I continued the experiment till the proportion was reduced to $\frac{1}{2} \frac{1}{0}$ th part. It would appear tedious to detail thefe experiments, the moft interefting being already minutely defcribed. In the fame progreflive manner, by diminining the 
the dofe of carbon, the metallic refult approached more and more to the foftnefs of malleable iron, though by no means poffeffed of all its properties. In this feries of experiments, iron prefented with $; \div$ th part its weight of charcoal was found to form very foft theel fit for making fciffars, \&ce, which, in a good workman's hands, would have doubled, welded, and formed a very perfect point, afterwards hardening fo as to difplay a beautiful clofe break of fteel. By ufing the following precaution, it was even found capable of welding perfectly to iron. Two flat bars of a fimilar thape, one of this quality of fteel, and 'ne of good malleable iron, were put under the hammer with a good welding heat. After a few light bl iws, the junction was completely made. The united bars were allowed to cool without further hammering till the thade of heat was bright red. The whole piece was then drawn out in a folid compact form, whofe fracture, when cold, prefented a complete junction of the iron and fteel, exhibiting at the fame time their refpective grains.

When iron is prefented in fuf $\mathbf{n}$ to $\frac{x}{3}+\mathrm{t}$ th or $\frac{2}{3}$, th part of its weight of charcoal, the refulting product occupies a kind of middle ftate betwixt malleable iron and fteel. It then welds with facility, and, provided the precaution formerly mentioned is attended to, may be joined either to iron or fteel, at a very high welding heat. Thus combined with carbon, it is ftill fufceptible of hardening a little, but without any great alteration in the fracture. It poffeffes an uncommon degree of ftrength and tenacity, capable of an exquifite degree of polith, arifing from its complete folidity and the purity of fracture conveyed to it by fufion.

When the dofe of carbon is further diminifhed, and in the ratio of this diminution, the fame feel or iron becomes more and more red thort, and lefs capable of cohefion under a welding heat, fo that, when the proportion is reduced to ${ }_{2} \frac{x}{0}-$ th part the weight of the iron, the quality refulting is nearly analogrous to the fufion of iron per je, or that obtained by the funion of iron and earths.

It will appear evident from the refult of thefe and former experiments, that crude iron and fteel only differ from each other in the proportions of the carbon they contain. In the details now before us, charcoal alone is ufed in addition to the malleable iron as pure as is ever made, to effect every principal ftage or modification of the metal. Hence we conclude, that

Iron femi-fteelified is made with, charcoal, is th part.

Soft caft fteel, capable of welding, with, - $\frac{1}{2} \sigma^{\text {th }}$

Caft fteel, for common purpofes, with, - $\frac{1}{30}$ th 
Caft fteel requiring more hardnefs, with, of charcoal, - $\quad-\quad{ }_{5}^{x}$ th part.

Steel capable of ftanding a few blows, but quite unfit for drawing, unfit for drawing, -
Firft approach to a fteely granulated fracture, is ${ }_{\frac{1}{5} \div}^{\frac{1}{3}}$ th
from

White caft iron

Mottled caft iron

Carbonated caft iron

And fupercarbonated crude iron when any greater quantity is ufed.

Although this is the quantity of charcoal neceffary to form thefe various qualities of metal by this mode of fynthefis, yet we are by no means authorized to conclude that this is the proportion of real carbonaceous matter taken up by the iron, feeing that in experiments No. I. to No. VI. inclufive, the weight gained by the iron was upon the average equal only to $\frac{\mathbf{I}}{2 \mathrm{I}_{\frac{1}{T}}^{s}}$ th part; whereas the charcoal which difappeared in the different fufions amounted to 6I.I per cent. of the original quantity introduced along with the iron.

In the fucceding experiments the following differences are remarkable:

No. VII. Charcoal ufed $\frac{1}{45}$ th - Iron gained $\frac{1}{3}$ th part.
No. VIII. No. VIII

No. IX.

No. X.

No. XI.

No. XII.

No. XIII.

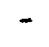

$$
\begin{aligned}
& \frac{1}{15} \text { th } \\
& \frac{1}{2} \text { th } \\
& \frac{1}{25} \text { th }
\end{aligned}
$$

$\frac{\pi}{3}$ th to $\frac{x}{4} \frac{1}{0}$ th

$\frac{1}{2} \bar{s}$ th

$\frac{1}{20}$

$\frac{1}{12} \mathrm{th}$, or

No. XIV.

$$
\begin{aligned}
& \text { - } \frac{1}{30} \text { th - } \quad \frac{1}{122 \frac{x}{2}}
\end{aligned}
$$

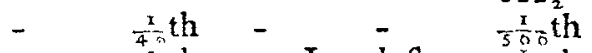

$$
\begin{aligned}
& \text { - } \quad \frac{1}{50} \text { th - Iron loft } \frac{3 \pi}{3 \frac{1}{8}} \text { th } \\
& \text { - } \frac{x}{\partial 0} \text { th - } \quad \frac{1}{36 \frac{5}{1} \sigma} \text { th } \\
& \text { - } \frac{x}{10} \text { th - - } \frac{1}{22 \frac{8}{10}} \text { th }
\end{aligned}
$$

From this we fee that when a proportion of charcoal equal to $\frac{7}{* 0}$ th part, and above, the weight of the iron is ufed, the latter always gains in weight; but when a more fparing proportion is introduced, room is left for the exertion of another affinity upon the metal, and it confequently and invariably lofes in weight proportioned to the diminution of the carbon. I have here further to remark upon the foregoing experiment, and upon the nature of experiments by fynthefis performed in this way in general, that the refults as to quality will differ materially when different portions of matter are ufed. So that an operator repeating the above experiments either in

Vol. XIII. No. 50. 


\section{On the different Proportions of Carbon, \&8.}

crucibles fmaller or larger, or with a greater or lefs weight of mixture, would not obtain the fame refults.

The formation of caft fteel in the large way, founded upon the refults of the foregoing experiments, affords an inconteftable proof of this. In futions of 18,22 , and $25 \mathrm{lbs}$. of iron each, we are obliged to increafe the dofe of carbon confiderably beyond that requifite in fmall experiments. To form fteel equal to that obtained in experiment XIII. wherein $\frac{1}{90}$ th of charcoal was ufed, $\frac{T}{55}$ th part is requifite to be introduced. For fteel fimilar to that in experiment XIV. $\frac{1}{6}$ th and $\frac{1}{70}$ th part are ufed. For fofter fteel $\frac{1}{50}$ th, whereas in the fmall experiment $\frac{1}{1}=$ th part was fufficient. If in the manufacturing a fmall extra quantity of carbon is requifite, this if faved by the comparatively fmall lofs fuftained in the tranfmutation of the iron into fteel.

Many inftances have occurred in the firft fufion from a calt fteel pot in the large way, where $25 \mathrm{lbs}$. of iron, and its requifite proportion of carbon, not exceeding 50 th, have afforded an ingot of caft fteel weighing $24 \mathrm{lbs} .12,13,14$, and 15 ounces, being a lofs equal to no more than $\frac{2}{1 \frac{1}{10}}$ th, $\frac{1}{2} \frac{1}{60}$ th, $\frac{1}{3}$ th, $\frac{1}{4}$, th part the weight of the iron, whereas in experiments No. XIII. and XIV. the lors of metal amounted to $\frac{1}{31 \frac{5}{3}}$ the and $\frac{1}{228}$ th part the weight of the iron.

I Mall conclude this paper with a few remarks upon the frate in which carbon exifts in fteel and in crude iron.

When malleable iron is fufed with $\frac{1}{3} \tau^{2}$ th or $\frac{1}{1+\tau}$ th part of is weighi- of carbon, the refulting product is confiderably if elifed. The fracture is lighter in the colour than it fornerly was in the ftate of iron. When fufed with an 80 th to ${ }_{i}^{1} c^{2} \mathrm{t}$ th, fteel of an ordinary quality is produced, the fracture of the metal ftill becoming whiter. When the dofe of :arbon is increafed beyond this, the fteel becomes fo hard and denfe as to be unfit for hammering. The fracture now will be found approaching to the colour of filver, and lofing its granulated appearance, affuming, however, a cryftallized form. In this ftate the metal will be found to refift the hammer and file, and to be unfit for any purpofe. Increafe, however, the quantity of carbon to $\frac{1}{32}$ th or $\frac{1}{15}$ th, the refulting product is no longer deftitute of grain, nor poffeffed of the fame degree of hardnefs. The fracture will be found gray, and the furface eafly reduced by the pile. A further increale of the carbon is accompanied by an increafe of the properties. At $1-8 \mathrm{th}$ or $1-6 \mathrm{th}$, the filings of the metal, when thrown into water, leave a carbonaceous pellicle corering the whole furface, and of a confiderable thicknefs. 
Thus we find that carbon hardens iron till it arrives at the higheit pitch of denfity, which is indicated by the metal lofing grain, and affuming a cryftallized filvery fracture. At this point ur maximum we may conceive that the refpective proportions of mixtures are fo nearly balanced that the affinity exerted by the iron is juft fufficient to deoxidate the charcoal, and that hitherto nothing but pure carbon fimilar to the diamond has combined with the iron. If, however, the equilibrium is deftroyed by a larger portion of charcoal, then we find the affinity too weak to deoxidate the whole, and part of it unites in the ftate of an oxide of carbon; at firt conftituting a mottled fracture, and afterwards, as the dofe is increaled, all thofe deepening bluein gray thades peculiar to foft caft iron. Hence carbon or its oxide again foftens iron. It never, however, reftores the properties of forging or of hammering. One invariable law, however, is maintained, that the fufibility of iron under every circumitance and modification is in the ratio of the quantity of carbon united.

$\mathrm{XXV}$. Refearches relative to the Moon's Influence on the Atmofpbere and on the Variations of the Barometer. By C. Corтe, Member of different Learned Societies*.

$\mathrm{D}$ URING forty years ftudy of meteorology I have conftantly viewed, with a peculiar degree of intereft, the influence of the moon upon our atmof phere.

The opinion of this influence is founded upon a prejudice fo antient, that I thought it worth while to endeavour, by means of refearches and combinations of facts, eftablifhed on the bafis of obfervations contained in our regifters, to difcover, not a complete fyftem, but the proper data to conduet us, by degrees, to the folution of the problem.

The retults of my endeavours in this way may be perufed, Ift, in my Treatife on Meteorology, publifhed in 1774 , p. 186, 302, 317, note; 280, 606: 2dly, in my Memoirs on Meteorology, publifhed in 1788, vol. i. p. 100, \&c. vol. ii. p. 80: 3 dly, in the Journal de Pbyfique 1782 , part ii. p. 249 ; 1786, part i. p. 276; 1792, part ii. p. 272; 1793, part i. p. 279 ; 1800 , part i. p. 358 , part ii. p. 337 ; 1801, part i. p. $33^{8}$, part ii. p. $22 \mathrm{I}, 409$.

The new refearches which 1 now offer to the publia have

* From Yournal do Pby/anze. \&tc. tom. liv. Prairial, an. 10. L 2 